\title{
Um Modelo Unidimensional para Enchentes Fluviais baseado no Método das Diferenças Finitas
}

\author{
Lucas Eduardo de Jesus Lima ${ }^{1}$ \\ Leonardo Alves da Costa ${ }^{2}$ \\ Marco Donisete de Campos ${ }^{3}$ \\ Instituto de Ciências Exatas e da Terra, Campus Universitário do Araguaia, \\ UFMT, Barra do Garças - MT.
}

\begin{abstract}
Resumo. Enchentes são fenômenos naturais que ocorrem quando a vazão ultrapassa a capacidade de escoamento de um rio, provocando o extravasamento da água para as margens, provocando muitos prejuízos à população como perdas materiais, interrupção da atividade econômica e contaminação por doenças. Diante disso, a gestão de recursos hídricos por meio da modelagem e da simulação matemática constitui-se uma importante ferramenta de investigação [1]. O objetivo deste trabalho é simular numericamente enchentes fluviais através do Método das Diferenças Finitas para aproximação espacial das equações diferenciais. São apresentados resultados mostrando as variações na altura do rio, bem como a formação das ondas.
\end{abstract}

Palavras-chave. Modelagem fluvial, Diferenças Finitas, Equação de Burgers.

\section{Delineamento do Problema}

Para determinar a ocorrência de uma enchente, analisa-se a evolução temporal da altura do rio, dada pela função $S$, através das variações do escoamento médio de água. A análise é feita a partir da equação de Burgers invíscida [2]:

$$
S_{t}(x, t)+\frac{1}{2}\left(S^{2}(x, t)\right)_{x}=S_{t}(x, t)+S S_{x}(x, t)=0 .
$$

\section{Resultados Numéricos}

Consideremos um rio de comprimento $L=5$, medido em centenas de quilômetros, $t$ o tempo, $\Delta t$ o intervalo de tempo, simulamos os saltos que caracterizam a enchente.

\footnotetext{
${ }^{1}$ lucaseduardocivil@hotmail.com

${ }^{2}$ leonardo_alves95@hotmail.com

3 mcampos@ufmt.br
} 
Como resultado, temos que as ondas de enchentes se propagam rio abaixo, sendo mantido fixo, ao longo do tempo, o volume total do rio, o que caracteriza um esquema conservativo, segundo as Figuras 1 e 2:

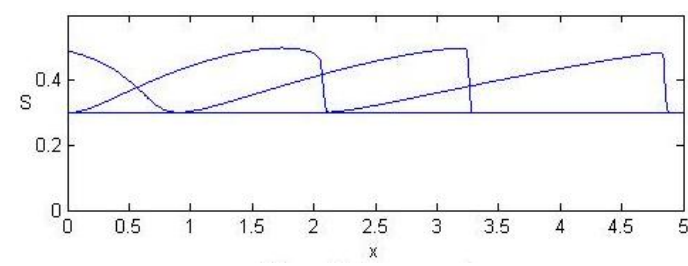

(a)

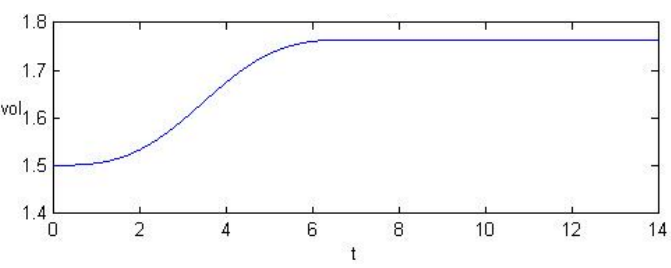

(b)

Figura 1: (a) Solução numérica da Equação (1), para $t=3,7,10$ e 14 dias, $\Delta t=0,005$ e $\Delta x=0,005$ e (b) volume total $\left(\mathrm{em}_{10} 0^{7} \mathrm{~m}^{3}\right)$ de água.

A solução permite identificar as variações na altura do rio e a formação das ondas, as quais definem uma inundação. Refinando espacialmente e temporalmente a malha, obtemos uma solução na qual essas ondas de enchente tornam-se cada vez mais verticais, conforme as Figuras 3 e 4:

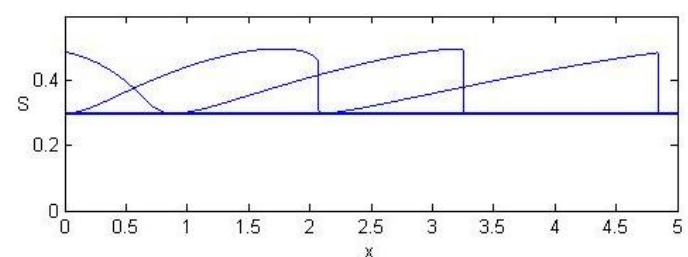

(a)

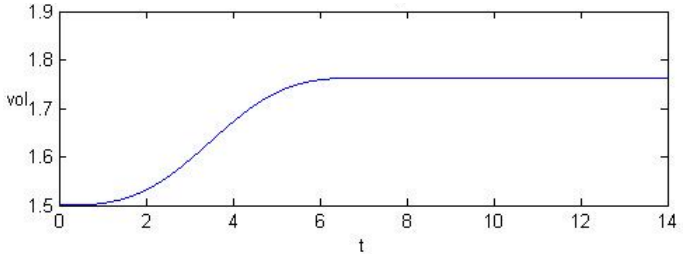

(b)

Figura 2: (a) Solução numérica da Equação (1), para $t=3,7,10$ e 14 dias, $\Delta t=0,00005$ e $\Delta x=0,0005$ e (b) volume total $\left(\mathrm{em}_{10} 0^{7} \mathrm{~m}^{3}\right)$ de água.

A aplicação do método numérico no problema de enchentes em rios possibilitou obter, através da solução de Burgers, previsões confiáveis sobre a evolução temporal da altura do rio, podendo servir de alerta para uma população ribeirinha acerca de uma inundação, evitando-se, assim, perdas humanas e materiais.

\section{Referências}

[1] J.S.A. Carmo, Modelação em Hidráulica Fluvial e Ambiente, Imprensa da Universidade de Coimbra, (2004).

[2] A. Nachbin e E. Tabak, Equações Diferenciais em Modelagem Matemática Computacional, $21^{\circ}$ Colóquio Brasileiro de Matemática: Minicurso IMPA, (1997). 